Trade in Trash: A Political Economy Approach

JAMES H. CASSING

NGO VAN LONG

Allier savoir et décision 


\section{$\checkmark$ CIRANO Knowledge into action}

Center for Interuniversity Research and Analysis on Organizations

The purpose of the Working Papers is to disseminate the results of research conducted by CIRANO research members in order to solicit exchanges and comments. These reports are written in the style of scientific publications. The ideas and opinions expressed in these documents are solely those of the authors.

Les cahiers de la série scientifique visent à rendre accessibles les résultats des recherches effectuées par des chercheurs membres du CIRANO afin de susciter échanges et commentaires. Ces cahiers sont rédigés dans le style des publications scientifiques et n'engagent que leurs auteurs.

CIRANO is a private non-profit organization incorporated under the Quebec Companies Act. Its infrastructure and research activities are funded through fees paid by member organizations, an infrastructure grant from the government of Quebec, and grants and research mandates obtained by its research teams.

Le CIRANO est un organisme sans but lucratif constitué en vertu de la Loi des compagnies du Québec. Le financement de son infrastructure et de ses activités de recherche provient des cotisations de ses organisations-membres, d'une subvention d'infrastructure du gouvernement du Québec, de même que des subventions et mandats obtenus par ses équipes de recherche.

\section{CIRANO Partners - Les partenaires du CIRANO}

Corporate Partners - Partenaires corporatifs

Autorité des marchés financiers

Bank of Canada

Bell Canada

BMO Financial Group

Business Development Bank of Canada

Caisse de dépôt et placement du Québec

Desjardins Group

Énergir

Hydro-Québec

Innovation, Science and Economic Development Canada

Intact Financial Corporation

Manulife Canada

Ministère de l'Économie, de la Science et de l'Innovation

Ministère des finances du Québec

National Bank of Canada

Power Corporation of Canada

PSP Investments

Rio Tinto

Ville de Montréal

Academic Partners - Partenaires universitaires

Concordia University

École de technologie supérieure

École nationale d'administration publique

HEC Montréal

McGill University

National Institute for Scientific Research

Polytechnique Montréal

Université de Montréal

Université de Sherbrooke

Université du Québec

Université du Québec à Montréal

Université Laval

CIRANO collaborates with many centers and university research chairs; list available on its website. Le CIRANO collabore avec de nombreux centres et chaires de recherche universitaires dont on peut consulter la liste sur son site web.

(C) August 2020. James H. Cassing, Ngo Van Long. All rights reserved. Tous droits réservés. Short sections may be quoted without explicit permission, if full credit, including (C) notice, is given to the source. Reproduction partielle permise avec citation du document source, incluant la notice ().

The observations and viewpoints expressed in this publication are the sole responsibility of the authors; they do not necessarily represent the positions of CIRANO or its partners. Les idées et les opinions émises dans cette publication sont sous l'unique responsabilité des auteurs et ne représentent pas nécessairement les positions du CIRANO ou de ses partenaires. 


\title{
Trade in Trash: A Political Economy Approach *
}

\author{
James H. Cassing ${ }^{\dagger}$, Ngo Van Long $\not{*}$
}

\begin{abstract}
We study how the opportunity to trade in trash might influence the equilibrium outcome when the tax on the externality is determined by a political economy process. In our model, individuals have heterogeneous preferences for environmental quality, and there is a leakage when funds are transferred from the pressure groups to the politicians. When hard-core environmentalists and capitalists are organized interest groups while moderate environmentalists are not organized, we find that the politically chosen tax on the externality is below the optimal Pigouvian level. The opportunity to export waste in unlimited quantities, but at a price, is not the environmentalists' panacea and does not eliminate political social tension and suboptimal results.
\end{abstract}

Keywords: Trade in Trash, Interest Groups, Externalities, Environmental Lobby, Political Economy, Trade and Environment

JEL Codes: F18, D72

\section{Résumé}

Nous étudions comment l'opportunité d'exporter des déchets pourrait influencer le résultat de l'équilibre lorsque la taxe sur l'externalité est déterminée par un processus d'économie politique. Dans notre modèle, les individus ont des préférences hétérogènes pour la qualité de l'environnement, et il y a une fuite lorsque les fonds sont transférés des groupes de pression aux politiciens. Lorsque les environnementalistes et les capitalistes purs et durs sont des groupes d'intérêts organisés alors que les environnementalistes modérés ne sont pas organisés, nous constatons que la taxe politiquement choisie sur l'externalité est inférieure au niveau pigouvien optimal. La possibilité d'exporter des déchets en quantités illimitées, mais à un prix, n'est pas la panacée des écologistes et n'élimine pas les tensions politiques sociales et les résultats sousoptimaux.

Mots-clés : Commerce des déchets, Groupes d'intérêt, Externalité, Lobby environnemental, Économie politique, Commerce et environnement

Codes JEL : F18, D72

\footnotetext{
* Acknowledgement: This research is supported by research grants from Canada's Social Sciences and Humanity Research Council (SSHRC) and Fonds de Recherche du Québec- Société et Culture (FRQSC).

$\dagger$ Department of Economics, University of Pittsburgh. E-mail: jcassing@ pitt.edu.

* CIRANO and Department of Economics, McGill University. E-mail: ngo.long@mcgill.ca.
} 


\section{Introduction}

Recently some appreciation - and alarm - has been given to the recognition that some externalities are traded internationally either directly or indirectly. Today, there are shocking scenes of imported plastic refuse piled high in neighborhoods of South and Southeast Asia, especially in India, the Philippines, Malaysia, and Indonesia. And there is now extensive documentation of large quantities of waste being exported, sometimes more harmful than just refuse but misrepresented, or simply dumped into the ocean (see Cassing and Kuhn, 2003a,b,c). More generally, beyond such tradeable waste, other examples include robust international exports/imports of toxic chemicals, nuclear waste, and other unsavory substances. This trade is different from transnational pollution such as smoke blowing across borders in the sense that the externality can be consciously packed and shipped anywhere in the world that accepts it. Also, and somewhat related, it is recognized that that climate change and world order represent both global externalities and a bone of contention as to who benefits and who should pay. A related observation is that public good externalities (such as national defense for a region) can be bought and sold.

This raises the issue as to what policies are appropriate for international trade in externalities. The de facto policy approach to date has been a bit cluttered and uncertain. Tools include international treaties and accords, as well as individual country policies of taxes and restrictions. This paper takes a different approach: we explore the issue of how the opportunity to trade in trash influences the equilibrium outcome given that the tax on waste is determined by a political economy process characterized by balancing competing interests of various pressure groups. In this respect, our paper embraces the political economy paradigm (Hillman, 2019). In our model, individuals have heterogeneous preferences for environmental quality as well as heterogeneous endowments of capital and labor.

By way of focus, we present a stylized theoretical model with a negative externality that is produced in conjunction with but is separable from a consumed commodity and which may enter into trans-border export or import for disposal - think plastic waste. Because of the 
opportunity to trade in trash, there is no reason why the externality and the consumption of the desired properties of the commodity need occur at the same location. One could consume a soft drink in home country $H$ and export the unsightly, environmentally damaging packaging to foreign country F. (Of course, this could happen inter-regionally within a country as well, and is in fact a contentious issue between municipalities and states/provinces within many countries.)

Section 2 offers a brief review of the related literature. As a benchmark for comparision, in Section 3 we present a closed economy model and characterize the efficient allocation under a benevolent social planner that maximizes social welfare under the "control and command" scenario. Moreover, we also show how that allocation can be achieved in a perfectly competitive market with an appropriately chosen Pigouvian tax on the externality. Section 4 turns to the case where a benevolent social planner does not exist, and a tax rate is determined by a government that balances the interests of opposing pressure groups. Section 5 then introduces an open economy where the externality is a tradeable entity. Section 6 discusses possible extensions of the model.

\section{Related literature}

There is a large literature that links international trade and the environment (see Siebert et al. 1980, Bommer and Schulze 1999, Schleich 1999, Fredriksson 1999, Copeland and Taylor 2004, Rauscher 2015). Hillman and Ursprung (1992, 1994) studied the political economy of trade policy with environmental interest groups. They distinguished between environmentalists who care only about local pollution (or are NIMBYs) and those who have global concerns. In our model there are only NAMBYs (not in my backyard).

Earlier papers that specifically deal with trade in trash and transferable externalities include Shogren and Crocker (1991) and Rauscher (2001). Shogren and Crocker (1991) demonstrate that noncooperative behavior will lead to overprotection if self-protection implies transferring the externality to another agent. If self-protection filters or dilutes the 
externality, then noncooperation results in underprotection. Their results suggest that coordination of protection activities among agents will enhance the overall gains from environmental policy in the European Single Internal Market. Rauscher (2001) presents a theoretical analysis of trade in toxic waste. He argues that "in a first-best world trade is indeed beneficial to all parties involved although the object of the trade consists of dangerous substances." However, when account is taken of imperfections such as regulatory and enforcement deficits and asymmetric information, international trade may be harmful.

More recent papers on trade in trash include Cassing and Kuhn (2003a,b,c), and Baggs (2009). Baggs (2009) uses a gravity trade model to empirically test the pollution haven hypothesis regarding trade in hazardous waste, according to which poorer countries have the comparative advantage in accepting toxic waste. This hypothesis has been summarized by the following excerpt from a memo of World Bank chief economist Lawrence Summers, reprinted in an issue of The Economist (1992):

"I think the economic logic behind dumping a load of toxic waste in the lowest wage country is impeccable and we should face up to that (...). I' ve always thought that the under-populated countries in Africa are vastly under-polluted."

The econometric analysis in Baggs (2009, p. 12) provides some evidence that "countries with high incomes, and by extension more costly environmental regulations, do accept less foreign hazardous waste for disposal within their borders," but at the same time, "low income countries on average do not have a comparative advantage in hazardous waste disposal." It should be noted, however, that Baggs' econometric model is built along the conventional economic line, ignoring important factors such as pressure groups, campaign contributions, etc., which one finds in the econometric works that test political economy hypotheses, such as Baldwin and Magee (1998), Goldberg and Maggi (1999), and Gawanda and Bandyopadhay (2000).

Our model follows the political economy tradition of trade policy (Hillman 1982, Grossman and Helpman 1994, Ethier and Hillman 2019). A particular characteristic of our model 
is that individuals have heterogeneous preferences.

\section{The basic model}

We begin with a stylized model of a closed economy (called the Home country) and a characterization of the welfare maximizing allocation. The economy has two sectors: a clean sector, which produces a numeraire good, and an externality-ridden sector, which produces a manufactured good that is accompanied by an externality-generating by-product. The easiest interpretation of the externality-ridden sector is as follows. A manufacturing sector produces a packaged product in tandem with plastic waste which is unsightly and practically impossible to destroy, but of no value in consumption. (Obviously, there are many paths to pursue - recycling, etc. - which we rule out.) The Home country is populated by $n$ individuals who have heterogeneous preferences for environmental quality.

We choose a two-sector formulation because efficient factor allocation is best illustrated in such a framework. For simplicity, we assume that labor is perfectly mobile across sectors. To keep our two-sector model as simple as possible, we assume that the clean sector uses labor as the only input: one unit of labor produces $w$ units of the numeraire good. The second sector uses capital and labor to produce a manufacturing output, $Y$, under a neoclassical production function $Y=F(K, L)$, where $K$ is capital, and $L$ is labor employed in this sector. The output $Y$ has a joint-product called "trash". For simplicity, we assume an one-to-one relationship between trash and manufacturing output: the volume of trash, $T$, is equal to the volume of output, $Y$.

The economy is endowed with a fixed supply of of capital, $\bar{K}$, and a fixed supply of labor, denoted by $\bar{L}$. We assume that full employment prevails. Thus, if an amount $L \leq \bar{L}$ is allocated to the manufactured sector, then $Y=F(\bar{K}, L)$ and the output of the numeraire good is $X=w[L-L] \geq 0$. (In what follows, we set $w=1$ without loss of generality.) Since $K \leq \bar{K}$ and $L \leq \bar{L}$, the maximum feasible output of the manufactured good is $\bar{Y}=F(\bar{K}, \bar{L})$. We assume that $F(K, L)$ exhibits constant returns to scale, with positive and dimisnishing 
marginal products and convex isoquants. Specifically, we assume that $F_{L}(\bar{K}, 0)=\infty$ and $F(0,0)=0$.

The economy is populated by a large number of individuals, $n$. Each individual is endowed with $\bar{\ell}$ units of labor, where $n \bar{\ell}=\bar{L}$. They supply their labor inelastically. Let $U(x, y)$ denote the utility from consuming a consumption bundle $(x, y)$. For simplicity, we assume that $U$ is linear in numeraire good, and strictly concave in the manufactured good. Thus, if individual $i$ consumes $x_{i}$ units of the numeraire good and $y_{i}$ units of the manufactured good, her utility is

$$
U_{i}=x_{i}+u\left(y_{i}\right)
$$

where $u^{\prime}>0$ and $u^{\prime \prime}<0$. An individual's welfare, $W_{i}$, is defined as her utility $U_{i}$ minus her discomfort which arises from seeing the pollution in her country. The pollution is denoted by $Z$, and, in the case of a closed economy, $Z=T$. (Later, when we consider trade in trash, then $Z=T-Q$ where $Q$ is the amount of trash the Home country exports to the Foreign country.) We assume that individuals are heterogeneous in their levels of discomfort: individual $i$ 's discomfort is $\beta_{i} D(Z)$, where $D(Z)$ is a positive and convex function, with $D^{\prime}(0)=0$, and $D^{\prime}(Z)>0$, and $D^{\prime \prime}(Z)>0$ for all strictly positive $Z>0$. The parameter $\beta_{i}>0$ is called the individual's "strength of preference" for a clean environment. In general, $\beta_{i} \neq \beta_{j}$ for any two individuals $i, j$. Then

$$
W_{i}\left(x_{i}, y_{i}, Z\right)=x_{i}+u\left(y_{i}\right)-\beta_{i} D(Z)
$$

The marginal social cost of waste is

$$
\sum_{i=1}^{n} \beta_{i} D^{\prime}(Z) \equiv \sigma D^{\prime}(Z)
$$

\subsection{Welfare maximizing allocation under the control-and-command scenario}

We now consider a benchmark scenario in which a benevolent social planner directly deter-

mines both (i) the allocation of labor across sectors, and (ii) each individual's consumption 
of the two goods. The planner maximizes social welfare, $W^{S}$, defined as the sum of the welfare levels of all residents, i.e.,

$$
W^{S}=\sum_{i=1}^{n} W_{i}=\sum_{i=1}^{n}\left[x_{i}+u\left(y_{i}\right)\right]-\sum_{i=1}^{n} \beta_{i} D(Z)
$$

subject to $\sum_{i=1}^{n} y_{i}=Y=F(\bar{K}, L), Z=Y$, and $X=\bar{L}-L$. In order to ensure that in equilibrium both goods are produced and consumed in strictly positive amounts, we make the following assumption:

Assumption A1: (i) $u^{\prime}(0)-\sigma D^{\prime}(0)>0$, (ii) $u^{\prime}(F(\bar{K}, \bar{L}) / n)<1 / F_{L}(\bar{K}, \bar{L})$.

The solution is simple. Since $u($.$) is strictly concave, we must have, at the social optimum,$ $y_{i}=F(\bar{K}, L) / n$. Therefore the problem reduces to finding the labor allocation $L$ that maximizes the following expression

$$
W^{S}=\bar{L}-L+n u(F(\bar{K}, L) / n)-n \bar{\beta} D(F(\bar{K}, L))
$$

where $\bar{\beta} \equiv(1 / n) \sum_{i=1}^{n} \beta_{i} \equiv \sigma / n$. The first order condition is

$$
1-\left[u^{\prime}\left(\frac{F(\bar{K}, L)}{n}\right)-\sigma D^{\prime}(F(\bar{K}, L))\right] F_{L}=0
$$

where $F_{L}$ denotes the marginal product of labor in manufacturing. ${ }^{1}$ Thanks to Assumption A1, we immediately obtain the following Result:

Result 1: The welfare maximizing allocation of labor to the externality-ridden sector is the unique $L^{*}>0$ that satisfies the following condition:

$$
u^{\prime}\left(\frac{F(\bar{K}, L)}{n}\right)-\sigma D^{\prime}(F(\bar{K}, L))=\frac{1}{F_{L}(\bar{K}, L)} \text { where } \sigma \equiv n \bar{\beta}
$$

The consumption allocation is as follows: each consumer is assigned a fraction $1 / n$ of the aggregate manufacturing output $Y^{*} \equiv F\left(\bar{K}, L^{*}\right)$, and it is a matter of indifference to the social planner (who cares only about the sum of individual welfare levels) as to how the aggregate output of the numeraire good, $X^{*}=\bar{L}-L^{*}>0$, is divided among the $n$ consumers.

\footnotetext{
${ }^{1}$ The second order condition is satisfied because $u^{\prime \prime}<0, D^{\prime \prime}>0$ and $F_{L L}<0$.
} 
Proof of Result 1: We can mentally picture the graph of the left-hand side (LHS) and that of the right-hand side (RHS) of equation (7), where the horizontal axis represents $L$ (which can take on any value between 0 and $\bar{L}$ ). The graph of the LHS of equation (7) is downward sloping. Due to Assumption A1, at $L=0$, the LHS takes the value $u^{\prime}(0)-\sigma D^{\prime}(0)>0$, and at $L=\bar{L}$, its value is smaller than $1 / F_{L}(\bar{K}, \bar{L})$. Next, consider the graph of the RHS of equation (7). This graph is upward sloping. At $L=0$, the RHS takes the value 0 , and at $L=\bar{L}$, its value is $1 / F_{L}(\bar{K}, \bar{L})$. It follows that the two curves intersect at a unique value $L^{*}$, with $0<L^{*}<\bar{L}$.

Example 1.1 Let $Y=F(K, L)=2 K^{1 / 2} L^{1 / 2}, D(Z)=\frac{1}{2} Z^{2}$, and $u(y)=A y-(b / 2) y^{2}$, with $A>0$ and $b>0$. Let $\bar{K}=1$.Then $F_{L}(\bar{K}, L)=L^{-1 / 2}$ and the RHS of equation (7) takes the value $L^{1 / 2}$, which is zero at $L=0$ and is $(\bar{L})^{1 / 2}$ at $L=\bar{L}$. (Later, for numerical illustrations, we will use the following specification of parameter values: $b=1, \sigma=2, n=$ $10, \bar{L}=20)$.

Then the socially optimal allocation of labor to manufacturing is

$$
L^{*}=\left(\frac{n A}{n+2 b+2 \sigma n}\right)^{2}<\bar{L}
$$

and manufacturing output is

$$
Y^{*}=2\left(L^{*}\right)^{1 / 2}=\frac{2 n A}{n+2 b+2 \sigma n} .
$$

For a numerical illustration, suppose that $A=5, n=10, b=1, \sigma=2$, and $\bar{L}=20$, then $L^{*}=$ 0.92456 , and marginal physical product of labor in manufacturing is 1.04 . Output is $Y^{*}=1$. $9231, Y^{*} / n=0.19231$, marginal utility of manufacturing consumption is 4.8077 , marginal social cost of pollution is $\sigma Y^{*}=3.8462$. It can be verified that the difference between $u^{\prime}$ and $\sigma Y^{*}$ (i.e., $4.8077-3.8462$ ) is equal to the inverse of the marginal product of labor in manufacturing, 0.9615 . The output of the numeraire good sector is $20-0.92456=19.075$. At the planner's solution, the social welfare level is

$$
W^{S}=\bar{L}-L+n u(F(\bar{K}, L) / n)-\sigma D(F(\bar{K}, L))=24.807 .
$$




\subsection{Welfare maximization in a market economy with a Pigouvian $\operatorname{tax}$}

It is straightforward to see that the optimal allocation of labor (depicted in Result 1) can be achieved in a private-ownership market economy guided by a Pigouvian tax on the output of the manufactured good. We assume that each individual is endowed with $\bar{\ell}$ units of labor, and $\bar{L}=n \bar{\ell}$. Capital is owned by $m_{1}$ individuals, where $m_{1}<n$. Firms are perfectly competitive. They take all product prices and factor prices as given. No individual has any market power. Moreover, we assume that although consumers dislike seeing waste lying around, in formulating their individual consumption plan, they do not adjust their demand for the two consumption goods with the aim of influencing the level of aggregate waste in the economy. This behavior is quite 'rational' because a single individual's consumption bundle has practically no effect on the aggregate outcome. ${ }^{2}$

We can prove the following Proposition.

Proposition 1: Assume that $\bar{\ell}$ is sufficiently such that each person's wage income, $\bar{\ell}$, is greater than the value of manufacturing output per person, i.e.,

$$
\bar{\ell}>u^{\prime}\left(\frac{F\left(\bar{K}, L^{*}\right)}{n}\right) \times \frac{F\left(\bar{K}, L^{*}\right)}{n}
$$

where $L^{*}$ is the socially optimal labor allocation described in Result 1. Then the social optimum can be achieved by a private-ownership market economy guided by a Pigouvian tax on manufacturing output, $t^{*}$, where $t^{*}$ is equal to the marginal social cost of waste,

$$
t^{*}=n \bar{\beta} D^{\prime}\left(F\left(\bar{K}, L^{*}\right)\right) \equiv \sigma D^{\prime}\left(F\left(\bar{K}, L^{*}\right)\right)
$$

and the tax revenue is distributed to all consumers as positive lump sum transfers. In this economy, manufacturing firms sell their output to consumers at the price $p_{c}^{*}$ per unit, where

$$
p_{c}^{*}=u^{\prime}\left(\frac{F\left(\bar{K}, L^{*}\right)}{n}\right)
$$

\footnotetext{
${ }^{2}$ Here, 'rationality' is understood as 'economic rationality'. Even though it is possible to argue that economic rationality (at the individual level) can be 'irrational' in the aggregate, in this paper we do not deal with this issue. For some recent discussion of this qualification and and a review of the related literature on Kantian economics, see, for example, Long (2020) and Grafton et al. (2017).
} 
and manufacturing firms' revenue per unit is $p_{f}^{*}$ where

$$
p_{f}^{*}=p_{c}^{*}-t^{*}
$$

Proof: The proof is straightforward. (It is available upon request.)

Example 1.2. We retain the functional specifications of example 1.1. At any given tax $t$ per unit of manufacturing ouput, firms equate the after tax value of marginal product of labor to the wage rate, taking the consumer price as given: $\left(p_{c}-t\right) F_{L}=1$. Consumers equate $u^{\prime}(y)$ to $p_{c}$. Thus, in a competitive equilibrium such that everyone consumes the same amount of the manufactured good, we must have

$$
u^{\prime}\left(\frac{F(\bar{K}, L)}{n}\right)-t=\frac{1}{F_{L}(\bar{K}, L)} \text { i.e., } A-\frac{b}{n}\left(2 L^{1 / 2}\right)-t=L^{1 / 2}
$$

Plug the socially optimal value $L^{*}$ in example 1.1 into the above equation, we can determine the Pigouvian tax per unit of manufacturing output, which is equal to the marginal social cost of pollution: $t^{*}=3.8462=\sigma Y^{*}$. The total tax revenue is $t^{*} Y^{*}=\sigma\left(Y^{*}\right)^{2}=3$. $8462 \times 1.9231=7.3966$. Each person obtains a lump sum redistribution amount 0.7396.

A worker's wage income is $\bar{L} / n=2$. The consumption of manufacturing good per person is 0.1923. Consumer's price is $u^{\prime}=5-0.1923=4.8077$. The expenditure per person on manufactured goods is $4.8077 \times 0.1923=0.92452$. A worker's spending on the numeraire good is $2+0.7396-0.92452=1.8151$. The aggregate return to capital is $\left(p_{c}-t\right) Y^{*}-w L^{*}=(4.8077-3.8462) \times 1.9231-0.92456=0.9245$ (which is equal to the manufacturing sector's wage bill, because our Cobb-Douglas share parameter is 1/2.) The output of the numeraire good sector is 19.075. Total expenditure on consumption goods is $19.075+4.8077(1.9231)=28.321$. It is equal to factor income plus lump sum transfers $(20+0.9245+7.3966)$. Total expenditure (in terms of the numeraire good) on manufacturing is $4.8077 \times 1.9231=9.2457$. Then the residual income after spending on manufacturing is $28.321-9.2457=19.075$. This is equal to employment in the numeraire good sector, $20-0.92456=19.075$. 


\section{The political economy equilibrium in a closed econ- omy}

In this section, we continue to assume that the Home country is a closed economy. The key motivation in this section derives from the fact that in the real world, it is possible but very unlikely that the social optimal allocation described in the preceding section is achieved. Governments do not set taxes to maximize a Benthamite social welfare function. A more realistic world view, often described as the "political economy approach", is that governments respond to demands by pressure groups. There are various ways of modelling how governments balance the interests of conflicting pressure groups. A possible short-hand formulation is that the government faces a "political support function" and it sets the level of various policy instruments so as to maximize that function. (See, e.g., Hillman (1982), Cassing and Hillman (1986), Long and Vousden (1991). In this paper, we follow a related approach used by Grossman and Helpman (1994). ${ }^{3}$ Their model, Protection for Sale, is based on the "common agency game" formulation of Bernheim and Whinston (1986). ${ }^{4}$ Our model differs from that of Grossman and Helpman (1994) in that (i) there is an externality generated in the production of the manufactured good, (ii) individuals have heterogeneous preferences for environmental quality, (iii) in the open economy case, the externality is tradeable in the world market, and (iv) there is a leakage factor which represents the social waste when funds are transferred from the pressure groups to the politicians.

\subsection{Capitalists versus environmentalists with heterogeneous envi- ronmental preferences}

There are $n$ individuals in this economy. Assume that each individual is endowed with $\bar{\ell}$ units of labor, and $\bar{L}=n \bar{\ell}$, and that capital is owned by $m_{1}$ individuals, where $m_{1}<n$. (For simplicity, we may assume that these $m_{1}$ individuals have equal endowment of capital,

\footnotetext{
${ }^{3}$ Grossman and Helpman (1994, p. 841) wrote that their model "provides the micro-analytic foundations for the reduced-form political support function."

${ }^{4}$ For a brief exposition of Grossman and Helpman (1994) and Bernheim and Whinston (1986), see Feenstra (2016, Chapter 10).
} 
$\bar{K} / m_{1}$.) Without loss of generality, we index individuals so that individuals with index $i$, where $i=1,2,3, . ., m_{1}$ are capital owners, and the remaining individuals, $j=m_{1}+1, m_{1}+$ $2, \ldots, n$ are not endowed with any capital. We call these $n-m_{1}$ individuals the non-capitalists. Each individual $i$ has an environmental preference parameter $\beta_{i} \geq 0$, and in general $\beta_{i} \neq \beta_{j}$ for any pair of individuals $(i, j)$. The average value of the preference parameter is denoted by $\bar{\beta}$, i.e.,

$$
\bar{\beta} \equiv \frac{1}{n} \sum_{i=1}^{n} \beta_{i}
$$

We assume that the community can be partitioned into three groups. Group 1 consists of $m_{1}$ individuals who own capital (we call them the capitalists). Although individual capitalists may differ from each other in terms of their $\beta_{i}$, we assume that on average, their preference parameter is not higher than the community's average, $\bar{\beta}$. Formally, we define $\bar{\beta}_{C}$ as the capitalists' average valuation of environmental quality,

$$
\bar{\beta}_{C}=\frac{1}{m_{1}} \sum_{i=1}^{m_{1}} \beta_{i} .
$$

and we assume that $\bar{\beta}_{C} \leq \bar{\beta}$.

Group 2 consists of $m_{2}$ non-capitalists with strong preferences for environmental quality. We call them the hard-core environmentalists. The average value of their preference parameter is denoted by $\bar{\beta}_{E}$, and we assume that $\bar{\beta}_{E} \geq \bar{\beta}$. Group 3 consists of $m_{3}$ non-capitalists whose preferences for environmental quality are moderate. We call them the moderate environmentalists. Their average is denoted by $\bar{\beta}_{M}$ where $\bar{\beta}_{M} \leq \bar{\beta}_{E}$. For concreteness, we make the following Assumption:

Assumption A2: On average, individuals that belong to Group 2 have the strongest preference for environmental quality, and the following ranking applies:

$$
\bar{\beta}_{C} \leq \bar{\beta} \leq \bar{\beta}_{M} \leq \bar{\beta}_{E}
$$

Manufacturing firms are perfectly competitive. They take the consumer price $p_{c}$, the factor prices, and the output tax $t$ as given. Each manufacturing firm $j$ chooses the input 
levels $\left(K_{j}, L_{j}\right)$ to maximize the firm's profit

$$
\Pi_{i}=\left(p_{c}-t\right) F\left(K_{j}, L_{j}\right)-w L_{j}-r K_{j}
$$

where $w=1$ is the wage rate (in terms of the numeraire good) and $r$ is the rental rate. Because of the constant returns to scale assumption, the size of each firm is indeterminate. However, since $\sum_{j} K_{j}=\bar{K}$, we know that for the manufacturing industry as the whole, the industry's employment of labor, $L$, is determined by maximizing the aggregate return to the capital stock $\bar{K}$ (the aggregate rent that accrue to capitalists), which we denote by $\pi$ :

$$
\pi \equiv \max _{L}\left(p_{c}-t\right) F(\bar{K}, L)-w L
$$

where $w=1$. The first order condition is that the value of marginal product of labor is equated to the wage rate:

$$
\left(p_{c}-t\right) F_{L}(\bar{K}, L)=w=1
$$

This means that the manufacturing-employment level that maximizes $\pi$ is a function of $p_{c}-t$. Denote this level by $\widehat{L}$. Then the aggregate output of the manufacturing sector is $F(\bar{K}, \widehat{L}) \equiv \widehat{Y}$. Then the (maximized) aggregrate return to capital is

$$
\widehat{\pi}\left(p_{c}-t\right)=\left(p_{c}-t\right) F(\bar{K}, \widehat{L})-w \widehat{L}=\left(p_{c}-t\right) \widehat{Y}-w \widehat{L}
$$

The total tax revenue is $t \widehat{Y}$. We assume that the tax revenue is redistributed to all individuals equally: each person receives a lump sum transfer of $t \widehat{Y} / n$.

Let us compute the income of the representative capitalist. It consists of her labor income, $\bar{\ell}$, her capital income, $\widehat{\pi} / m_{1}$, and the lump sum transfer $t \widehat{Y} / n$. Let $M_{k}$ denote this income:

$$
M_{k}=\widehat{\pi} / m_{1}+\bar{\ell}+t \widehat{Y} / n
$$

The representative capitalist chooses the consumption levels $x_{k}$ and $y_{k}$ to maximize the utility derived from consumption:

$$
\max _{x_{k}, y_{k}}\left[x_{k}+u\left(y_{k}\right)\right]
$$


subject to the budget constraint $x_{k}+p_{c} y_{k}=M_{k}$. Assuming that $M_{k}$ is large enough, and that $p_{c}<u^{\prime}(0)$, both goods will be consumed in strictly positive amounts, and the utilitymaximizing consumption bundle $\left(\widehat{x}_{k}, \widehat{y}_{k}\right)$ is given by

$$
u^{\prime}\left(\widehat{y}_{k}\right)=p_{c}, \text { and } \widehat{x}_{k}=M_{k}-p_{c} \widehat{y}_{k} .
$$

Equation (25) yields the consumer's Marshallian demand function, $y^{D}\left(p_{c}\right)$, for the manufactured good:

$$
\widehat{y}_{k}=\left(u^{\prime}\right)^{-1}\left(p_{c}\right) \equiv y^{D}\left(p_{c}\right)
$$

Substituting (25) and (26) into the direct utility function (24), we obtain the indirect utility function of the representative capitalist:

$$
V_{k}=M_{k}-p_{c} y^{D}\left(p_{c}\right)+u\left(y^{D}\left(p_{c}\right)\right)=M_{k}+S\left(y^{D}\left(p_{c}\right)\right)
$$

where $S\left(y^{D}\left(p_{c}\right)\right)$ is her Marshallian consumer's surplus:

$$
S\left(y^{D}\left(p_{c}\right)\right) \equiv u\left(y^{D}\left(p_{c}\right)\right)-p_{c} y^{D}\left(p_{c}\right)
$$

with the well-known property that

$$
\frac{d S}{d p^{c}}=-y^{D}\left(p_{c}\right)
$$

Let us now turn to the representative worker (defined as the person who does not own capital). Her income is

$$
M_{\ell}=w \bar{\ell}+t \widehat{Y} / n
$$

Again, we assume her income is high enough and $p_{c}<u^{\prime}(0)$, so that she finds it optimal to consume both goods. Then her utility-maximizing consumption bundle $\left(\widehat{x}_{\ell}, \widehat{y}_{\ell}\right)$ is given by

$$
u^{\prime}\left(\widehat{y}_{\ell}\right)=p_{c}, \text { and } \widehat{x}_{\ell}=M_{\ell}-p_{c} \widehat{y}_{\ell} .
$$

It follows that $\widehat{y}_{\ell}=\widehat{y}_{k}=y^{D}\left(p_{c}\right)$, and her indirect utility function is

$$
V_{\ell}=M_{k}-p_{c} y^{D}\left(p_{c}\right)+u\left(y^{D}\left(p_{c}\right)\right)=M_{\ell}+S\left(y^{D}\left(p_{c}\right)\right) .
$$


It is easy to show that for any given tax $t \geq 0$, the equilibrium employment level in the manufacturing sector, $\widehat{L}$, is uniquely determined.

In equilibrium, total consumption of the manufactured good must equal that sector's output $n y=F(\bar{K}, L)$. Thus,

$$
p_{c}=u^{\prime}(F(\bar{K}, L) / n)
$$

The equilibrium demand for labor in manufacturing is given implicitly by equation (21), which can be re-written as

$$
p_{c}-t=\frac{1}{F_{L}(\bar{K}, L)}
$$

That is, firms equate the net price, $p_{c}-t$, to the marginal cost (which is the wage divided by the marginal product of labor). Combining equations (33) and (34), we obtain a unique equation that determines $L$ as a function of $t$ :

$$
u^{\prime}(F(\bar{K}, L) / n)-t=\frac{1}{F_{L}(\bar{K}, L)}
$$

This relationship yields

$$
\left(u^{\prime}(F(\bar{K}, L) / n)-t\right) F_{L}=0
$$

We can now state the following Lemma.

Lemma 1: Given any tax rate $t$ per unit of the manufactured good, where $0 \leq t \leq$ $u^{\prime}(0)$, equation (36) determines the allocation of labor to manufacturing, $\widehat{L}(t)$, and yields the following comparative static results:

$$
\frac{d \widehat{L}(t)}{d t}=\frac{F_{L}}{\left[\frac{F_{L L}}{F_{L}}+\frac{\left(F_{L}\right)^{2} u^{\prime \prime}}{n}\right]}<0
$$

and

$$
\frac{d \widehat{Y}(t)}{d t}=\frac{\partial F}{\partial L} \frac{d \widehat{L}(t)}{d t}=\frac{1}{\left[\frac{F_{L L}}{\left(F_{L}\right)^{3}}+\frac{u^{\prime \prime}}{n}\right]}<0 .
$$

The equilibrium consumer price is $\widehat{p}_{c}(t)=u^{\prime}(\widehat{Y}(t) / n)$, with

$$
\frac{d \widehat{p}_{c}}{d t}=\frac{u^{\prime \prime}}{n} \frac{d \widehat{Y}(t)}{d t}>0
$$


and the equilibrium net price received by firms is $\widehat{p}_{f}(t)=\widehat{p}_{c}(t)-t$, with

$$
\frac{d \widehat{p}_{f}}{d t}=\frac{d \widehat{p}_{c}}{d t}-1=-\frac{F_{L L}}{\left(F_{L}\right)^{3}} \frac{d \widehat{Y}(t)}{d t}<0 .
$$

Proof: Applying the implicit function theorem to equation (36), we obtain eq. (37). Equations (38) and (39) follow immediately. Finally, to obtain eq. (40) we use

$$
\frac{d \widehat{p}_{f}}{d t}=\frac{u^{\prime \prime}}{n} \frac{d \widehat{Y}(t)}{d t}-1=\left[\frac{u^{\prime \prime}}{n}-\frac{1}{\frac{d \widehat{Y}(t)}{d t}}\right] \frac{d \widehat{Y}(t)}{d t} .
$$

Using Lemma 1, we can derive the following result:

Proposition 2: Assume that $u^{\prime}(0)>0$ and $u^{\prime}(F(\bar{K}, \bar{L}) / n)<1 / F_{L}(\bar{K}, \bar{L})$. Restrict attention to tax rate $t \geq 0$ is such that $u^{\prime}(0)-t>0$. Then for each $t \geq 0$ that satisfies this condition, there exists a unique employment level in manufacturing, $\widehat{L}(t)$, with $0<\widehat{L}(t)<\bar{L}$, such that the market is in equilibrium and all consumers buy both goods, provided that (i) $\bar{\ell}$ is large enough, and (ii) the tax revenue is redistributed equally to all consumers as lump sum transfers.

The equilibrium consumer price is

$$
\widehat{p}^{c}(t)=u^{\prime}(F(\bar{K}, \widehat{L}(t)) / n) \equiv u^{\prime}(\widehat{Y}(t) / n)
$$

and the resulting welfare level of capitalist $i\left(i=1,2, \ldots, m_{1}\right)$ is

$$
W_{i}=\widehat{\pi} / m_{1}+\bar{\ell}+t \widehat{Y} / n+S(\widehat{y})-\beta_{i} D(\widehat{Y})
$$

while that of non-capitalist $j$ (where $j=m_{1}+1, m_{1}+2, \ldots, n$ ) is

$$
W_{j}=\bar{\ell}+t \widehat{Y} / n+S(\widehat{y})-\beta_{j} D(\widehat{Y})
$$

Moreover, the equilibrium producer's price is

$$
\widehat{p}_{f}(t)=\widehat{p}_{c}(t)-t=u^{\prime}(F(\bar{K}, \widehat{L}(t)) / n)-t .
$$

Proof: Straightforward. Below is a sketch of the proof. Consider the equation

$$
u^{\prime}(F(\bar{K}, L) / n)-t=\frac{1}{F_{L}(\bar{K}, L)} .
$$


We can graph the RHS of eq. (46) as a function of $L$ for $L$ in the feasible interval $[0, \bar{L}]$. Clearly, $\frac{1}{F_{L}(\bar{K}, L)}$ is increasing in $L$. At $L=0$, the vertical intercept of the curve is 0 . As $L$ increases, $\frac{1}{F_{L}(\bar{K}, L)}$ increases, reaching the value $\frac{1}{F_{L}(\bar{K}, \bar{L})}$ at $L=\bar{L}$.

Next, we can graph the LHS of eq. (46) as a function of $L$. The graph is decreasing. At $L=0$, the LHS is $u^{\prime}(0)-t$, which is strictly greater than 0 , by hypothesis. As $L$ tends to $\bar{L}, u^{\prime}(F(\bar{K}, L) / n)$ reaches $u^{\prime}(F(\bar{K}, \bar{L}) / n)-t \leq u^{\prime}(F(\bar{K}, \bar{L}) / n)<1 / F_{L}(\bar{K}, \bar{L})$. Therefore the graph of the LHS intersects that of the RHS exactly once, at some $\widehat{L}<\bar{L}$.

If $\bar{\ell}$ is large enough, such that $\bar{\ell}>\widehat{p}_{c}(t) \widehat{Y}(t) / n$, each consumer will spend $\widehat{p}_{c}(t) \widehat{Y}(t) / n$ on the manufactured good, and $\bar{\ell}-\widehat{p}_{c}(t) \widehat{Y}(t) / n$ on the numeraire good.

Example 1.3 We retain the functional forms specified in example 1.1. Given any $t$ such that $0 \leq t<u^{\prime}(0)$, using eq. (35), we can solve for the corresponding employment level in the manufacturing sector $\widehat{L}(t)$,

$$
\widehat{L}(t)=\left(\frac{A-t}{1+\frac{2 b}{n}}\right)^{2}=\left(\frac{n(A-t)}{n+2 b}\right)^{2}
$$

This yields the competitive manufacturing output level,

$$
\widehat{Y}(t)=\frac{2 n(A-t)}{n+2 b}
$$

The corresponding consumers price $p_{c}$ and producers price $p_{f}$ are,

$$
\widehat{p}_{c}(t)=\frac{n A+2 b t}{n+2 b} \text { and } \widehat{p}_{f}(t)=\frac{n(A-t)}{n+2 b}
$$

with

$$
\frac{d \widehat{p}_{f}(t)}{d t}=\frac{1}{2} \frac{d \widehat{Y}(t)}{d t}<0 .
$$

\subsection{Organized interest groups and unorganized interest groups}

We have assumed that when individuals make their consumption decisions, they do so in isolation, taking the prices and their income as given, and without taking into account the (negligible) effect of their individual consumption demand on the industry output and waste 
level. This assumption is commonly made (see, for example Grossman and Helpman (1994), Long and Vousden (1991)). At the same time, it is not unreasonable to assume that groups of individuals are formed to further their interest by taking collective action to influence government policies.

Some groups can overcome the free-riding problem, and are able to require group members to contribute financial resources to further their group interest. We call these groups "organized interest groups." At the other extreme, some other groups are unorganized and do not take any collective action at all. In this paper, we investigate how the pressure exercised by an environmental lobby group and a capitalist group could result in a "political economy equilibrium", and we compare the outcome of this equilibrium with the benchmark outcome under a benevolent social planner (which was described in Proposition 1).

How do organized groups influence policies? We borrow the idea of "campaign contribution schedules" used in Grossman and Helpman (1994), which is an ingredient in the "common agency" game considered in Bernheim and Whinston (1986). In this game, each of the opposing organized groups offers to the government a payment of "money" (called campaign contribution) conditional on the government's announced tax rate in its policy platform. (In our model, we may suppose that a unit of money is equal to a unit of the numeraire good). If a group prefers low taxes, then the lower is the announced tax rate, the more campaign contribution it gives to the government. In contrast, if a group stands to gain (in terms of its own welfare) when the tax rate is higher, then its contribution will rise with the announced tax rate. A non-organized group, by definition, does not make any campaign contribution.

While the government values campaign contributions, it also cares about social welfare. We assume that the government's objective function is to maximize a weighted sum of the (net) Benthamite social welfare level and its (net) receipt of campaign contributions.

Now, given $t$, the welfare levels of Group 1, 2 and 3 are:

$$
J_{1}(t)=\sum_{i=1}^{m_{1}} W_{i}=m_{1}\left[\widehat{\pi}(t) / m_{1}+\bar{\ell}+t \widehat{Y}(t) / n+S\left(y^{D}\left(p_{c}(t)\right)\right)\right]-m_{1} \bar{\beta}_{C} D(\widehat{Y})
$$




$$
\begin{aligned}
& J_{2}(t)=\sum_{j=m_{1}+1}^{m_{1}+m_{2}} W_{j}=m_{2}\left[\bar{\ell}+t \widehat{Y}(t) / n+S\left(y^{D}\left(p_{c}(t)\right)\right)\right]-m_{2} \bar{\beta}_{E} D(\widehat{Z}) \\
& J_{3}(t)=\left(n-m_{1}-m_{2}\right)\left[\bar{\ell}+t \widehat{Y}(t) / n+S\left(y^{D}\left(p_{c}(t)\right)\right)\right]-m_{3} \bar{\beta}_{E} D(\widehat{Z})
\end{aligned}
$$

The social welfare is

$$
J(t)=J_{1}+J_{2}+J_{3}=n\left[\bar{\ell}+t \widehat{Y}(t) / n+S\left(y^{D}\left(p_{c}(t)\right)\right)\right]+\widehat{\pi}-n \bar{\beta} D(\widehat{Z}) .
$$

Let $\Lambda$ denote the set of organized groups, and let $\Lambda^{C}$ denote its complement (i.e. the set of unorganized interest groups). We will consider two cases. In case 1 , we have $\Lambda=\{1,2,3\}$ so that $\Lambda^{C}$ is the empty set. In case 2 , we have $\Lambda=\{1,2\}$ so that $\Lambda^{C}=\{3\}$.

Let $\psi_{h}(t)$ denote the contribution schedule of organized group $h \in \Lambda$. The net welfare of a group is its welfare minus its campaign contribution. Thus the net welfare of a group $h$ is

$$
\begin{gathered}
J_{h}^{n e t}=J_{h}-\psi_{h}(t), \text { if } h \in \Lambda \\
J_{h}^{n e t}=J_{h} \text { if } h \in \Lambda^{C} .
\end{gathered}
$$

We assume that when money is transferred from a pressure group, there is a "leakage factor" $\gamma$ which represents the loss of real resources that such activities engender, where $0<\gamma<1$. For example, if $\gamma=0.20$, then for every dollar transferred to the government, the latter only receives 80 cents. Thus, the government's net receipt of funds, $R(t)$, is

$$
R(t)=(1-\gamma) \sum_{h \in \Lambda} \psi_{h}(t)
$$

(In Grossman and Helpman (1994), there is no leakage, i.e., $\gamma=0$.)

When lobby groups make campaign contributions to the government, we must make a distinction between gross social welfare and net social welfare. Gross social welfare is

$$
J^{\text {gross }}(t)=J_{1}(t)+J_{2}(t)+J_{3}(t)
$$

while net social welfare is

$$
J^{n e t}(t)=J^{\text {gross }}(t)-\sum_{h \in \Lambda} \psi_{h}(t)
$$


The government chooses the tax rate $t$ to maximize a weighted sum of (i) net social welfare, and (ii) its net receipt of campaign contribution, with weights $\omega>0$ and $(1-\omega)>0$ respectively:

$$
G(t) \equiv \omega J^{n e t}(t)+(1-\omega)(1-\gamma) \sum_{h \in \Lambda} \psi_{h}(t)
$$

After re-arragment of terms, we obtain

$$
G(t)=\omega J^{g r o s s}(t)+((1-\omega)(1-\gamma)-\omega) \sum_{h \in \Lambda} \psi_{h}(t) .
$$

Let us define $\rho \equiv(1-\omega)(1-\gamma)-\omega$ and assume that $\rho>0 .{ }^{5}$ Then the problem of maximizing $G$ with respect to $t$ can be solved by maximizing the expression $\widetilde{G}(t)$ defined by

$$
\widetilde{G}(t)=\left(\frac{\omega}{\rho}\right) J^{\text {gross }}(t)+\sum_{h \in \Lambda} \psi_{h}(t) \equiv \delta J^{\text {gross }}+\sum_{h \in \Lambda} \psi_{h}(t)
$$

where $\delta>0$ is increasing in $\gamma$ (as long as $\rho$ remains positive).

The "common agency game" framework typically assumes that the government, facing the "announced contribution schedules", must take them as given (it cannot negotiate) and can only choose the policy level (here, $t$, but in a more general model, the levels of several policy variables). Thus, the pressure groups are "Stackelberg leaders" while the government simply reacts (i.e., it is a follower, or second mover). The game between the pressure groups is a simultaneous-play game that occurs at an earlier stage, called stage 1. We must look for a Nash equilibrium for stage-1 game. This might sound like a complicated game to solve. Fortunately, thanks to a result by Berheim and Whinston (1986), we can focus on contribution schedules that truthfully reflect the gains expected by the pressure groups. A simple formulation is that for all organized group $h$, its contribution $\psi_{h}(t)$ is equal to $J_{h}(t)$ minus a constant $B_{h}$ for values of $t$ such that $J_{h}(t)-B_{h} \geq 0$, and $\psi_{h}(t)$ is equal to zero for

\footnotetext{
${ }^{5} \mathrm{~A}$ sufficient condition for this is that both $\gamma$ and $\omega$ are sufficiently small.
} 
values of $t$ such that $J_{h}(t)-B_{h}<0$. This means that ${ }^{6}$

$$
\psi_{h}(t)=\max \left\{0, J_{h}(t)-B_{h}\right\} \text { for } h \in \Lambda \text {. }
$$

Using this result, we can re-write $\widetilde{G}$ as

$$
\widetilde{G}=\delta\left(J_{1}+J_{2}+J_{3}\right)+\sum_{h \in \Lambda} \max \left\{0, J_{h}(t)-B_{h}\right\}
$$

Now, assume for simplicity that in some neighborhood of the political economy equilibrium $t^{* *}$, we have $J_{h}\left(t^{* *}\right)-B_{h}>0$ for all organized groups. Then $t^{* *}$ must be the solution of the problem

$$
\max _{t}(1+\delta) \sum_{h \in \Lambda}\left[J_{h}(t)-B_{h}\right]+\delta \sum_{h \in \Delta^{C}} J_{h}(t) .
$$

In what follows, we solve for the political economy equilibrium under two cases. In case $1, \Lambda=\{1,2,3\}$, i.e., all groups are organized and make political campaign contributions. In case $2, \Lambda=\{1,2\}$ and $\Lambda^{C}=\{3\}$.

\subsection{Case 1: all interest groups are organized}

Let us find the solution for Case 1 , where $\Lambda=\{1,2,3\}$ and thus $\Lambda^{C}$ is the empty set. In this case, maximizing the objective function (65) is equivalent to maximizing gross social welfare $J$ :

$$
J(t)=n\left[\bar{\ell}+t \widehat{Y}(t) / n+S\left(y^{D}\left(p_{c}(t)\right)\right)\right]+\widehat{\pi}\left(p_{c}(t)-t\right)-n \bar{\beta} D(\widehat{Z}) .
$$

The first order condition yields

$$
\frac{d J(t)}{d t}=\widehat{Y}+t \frac{d \widehat{Y}}{d t}+n \frac{d S}{d p_{c}} \frac{d p_{c}}{d t}+\frac{d \widehat{\pi}}{d\left(p^{c}-t\right)}\left[\frac{d p_{c}}{d t}-1\right]-n \bar{\beta} D^{\prime}(\widehat{Y}) \frac{d \widehat{Y}}{d t}=0
$$

Now, recalling that $\frac{d \widehat{\pi}}{d\left(p^{c}-t\right)}=\widehat{Y}$ (by the envelope theorem), and $\frac{d S}{d p_{c}}=-y^{D}\left(p_{c}\right)=-\widehat{Y} / n$, equation (67) becomes

$$
\frac{d J(t)}{d t}=\widehat{Y}\left[1-\frac{d p^{c}}{d t}\right]+t \frac{d \widehat{Y}}{d t}+\widehat{Y}\left[\frac{d p^{c}}{d t}-1\right]-n \bar{\beta} D^{\prime}(\widehat{Y}) \frac{d \widehat{Y}}{d t}=0
$$

\footnotetext{
${ }^{6}$ Equation (63) implies that

$$
J_{h}^{n e t}(t) \equiv J_{h}(t)-\psi_{h}(t)=\min \left\{J_{h}(t), B_{h}\right\} \text { for } h \in \Lambda .
$$

that is, $B_{h}$ is the upper bound on the net welfare of organized group $h$. (See Grossman and Helpman (1994) and Mitra (1999) for discussion on reasonable determination of $B_{h}$.)
} 
which implies that the government chosen tax rate in the political economy equilibrium is equal to the marginal social cost of trash:

$$
t^{*}=n \bar{\beta} D^{\prime}(\widehat{Y}) \equiv \sigma D^{\prime}(\widehat{Y})
$$

Thus, the government's political economy tax rate is identical to the Pigouvian tax rate found in the previous subsection. However, there is a waste of real resources if the leakage factor $\gamma$ is positive. We state this result as Proposition 3:

Proposition 3: If all groups are organized pressure groups and they reach a Nash equilibrium in the political economy game where the government is the common agency, then the political economy tax on externality is equal to the Pigouvian one, and the allocation of factors of production is Pareto efficient. However, to the extent that the payment of campaign contributions is subject to a leakage factor $\gamma>0$, the political economy equilibrium involves a waste of real resources.

Example 1.4 For the utility function, the production function, and the pollution damage function $D(Z)$, we retain the functional forms specified in example 1.1. Then equation (69) shows that when all the three groups are organised, the government will react to their equilibrium contribution schedules by setting the tax rate equal to the marginal social cost of pollution:

$$
t=\sigma Y
$$

Using eq. (48), we know that the corresponding output level of the manufacturing sector is a function of $t$

$$
Y=\frac{2 n(A-t)}{n+2 b}
$$

Combining these two equations, we can solve for the equilibrium manufacturing output when all the three groups are organized:

$$
Y=\frac{2 n A}{n+2 b+2 n \sigma}
$$




\subsection{Case 2: group 3 is unorganized}

We now turn to the case in which only group 1 (the capitalists) and group 2 (the hard-core environmentalists) are organized pressure groups. Group 3 (the moderate environmentalists) is not organized. Then $\Lambda=\{1,2\}$ and $\Lambda^{C}=\{3\}$. In this case, we obtain the following Proposition:

Proposition 4: Under Assumption A2, if the moderate environmentalists are not organized then the political economy equilibrium tax on the externality that is below the optimal Pigouvian one.

Proof: When $\Lambda=\{1,2\}$ and thus $\Lambda^{C}=\{3\}$, it is convenient to define

$$
\lambda_{0} \equiv \frac{m_{1}+m_{2}}{n} \text { and } 1-\lambda_{0}=\frac{m_{3}}{n}
$$

where $\lambda_{0}$ is the fraction of the population that belongs to either organized group 1 or organized group 2. Then when the government chooses $t$ to maximizes it objective function (65), the following first order condition is obtained (see the Appendix for detailed derivation):

$$
\left(\delta+\lambda_{0}\right)\left[t-n \bar{\beta} D^{\prime}(\widehat{Y}(t))\right]+\left(1-\lambda_{0}\right)\left\{\left(n \bar{\beta}_{M}-n \bar{\beta}\right) D^{\prime}(\widehat{Y}(t))-\left(\frac{F_{L L}}{F_{L}^{3}}\right) \widehat{Y}(t)\right\}=0
$$

Since the term inside the curly brackets $\{\ldots\}$ is positive, it follows that $t<n \bar{\beta} D^{\prime}(\widehat{Y}(t))$.

Remark: Using the arguments in the proof of Proposition 4, we can actually state a stronger result (in the sense that Assumption A2 can be slightly relaxed):

Corollary: If group 3 is not organized and either (i) $n \bar{\beta}_{M}-n \bar{\beta} \geq 0$ or (ii) $n \bar{\beta}_{M}-n \bar{\beta}<0$ but $\left(-\frac{F_{L L}}{\left(F_{L}\right)^{3}}\right)+\left(n \bar{\beta}_{M}-n \bar{\beta}\right) \frac{D^{\prime}(\widehat{Y})}{\widehat{Y}}>0$, then the political economy equilibrium tax on the externality is below the optimal Pigouvian one.

Example 1.5 For the utility function, the production function, and the pollution damage function $D(Z)$, we retain the functional forms specified in example 1.1. Then

$$
\left(\frac{F_{L L}}{F_{L}^{3}}\right)=-\frac{1}{2}
$$

Define $\phi=\left(1-\lambda_{0}\right) /\left(\delta+\lambda_{0}\right), \sigma=n \bar{\beta}$ and $\sigma^{+}=n \bar{\beta}_{M}$, and $\varepsilon \equiv \sigma^{+}-\sigma>0$, we can rewrite 
the first order condition as

$$
t-\sigma \widehat{Y}(t)+\phi\left(\varepsilon \widehat{Y}(t)+\frac{1}{2} \widehat{Y}(t)\right)=0
$$

Let $\bar{L}=20, \sigma=2, \phi=0.5, \varepsilon=0.5, n=10, b=1, A=5$. Then, solving for $t^{* *}$, we get $t^{* *}=3.5714$.

Thus the political-economy equilibrium manufacturing output is

$$
Y(t)=\frac{2 n(A-t)}{n+2 b}=2.381
$$

the marginal social cost of pollution is $\sigma D^{\prime}(Y(t))=4$. 762. This confirm that $t^{* *}<\sigma D^{\prime}\left(Y^{* *}\right)$. The level of employment in manufacturing is 1.4173 , hence the output of the numeraire goods sector is 18.583 . The equilibrium consumers price is $p_{c}=4.7619$, the equilibrium producers price is $p_{f}=p_{c}-t=1.1905$. Consumption of manufactured good per person is 0.2381. The resulting gross social welfare is

$$
W^{S}=18.583+10\left(5 \times 0.2381-\frac{1}{2}(0.2381)^{2}\right)-(2.381)^{2}=24.535
$$

which is lower than the welfare level under the social planner (which was 24.807).

\section{The open economy case: trade in trash}

We now consider the case in which the Home country can "export" some (or all) of its trash to a foreign country. We consider two scenarios. In Scenario 1, Home can freely dump the trash in Foreign's territory (up to an upper bound $\bar{Q}>0$ ). In Scenario 2, Home can export as much trash as it wishes to, but it must pay Foreign a charge $\mu$ per unit of trash exported. In both scenarios, we compare the Home social planner's solution with the political equilibrium.

\subsection{Scenario 1: free dumping of trash, up to an upper bound}

Assume that up to $\bar{Q}$ units of trash can be dumped in the foreign country (Foreign), and that the Home country's residents do not care about the size of the trash heap in Foreign. It is as if Foreign gives to Home a "free export quota", $\bar{Q}$. Then the relationship between the 
aggregate trash that remains in Home and the trash generated by Home's manufacturing sector, $T$, is

$$
Z=\min \{0, T-\bar{Q}\}
$$

where $T=Y$. We will focus on the situation where the export quota $\bar{Q}$ is smaller than the closed economy's social optimum level of the output, $Y^{*}$ (which we characterized in Result 1). We suppose that consumers in Home have a distaste for the level of trash that remains in the Home country, but they do not care about the environmental damages in the foreign country.

\subsubsection{The optimal allocation under command and control (with limited free dumping)}

Now, consider a given "trash export quota" $\bar{Q}$, and assume that $0<\bar{Q}<Y^{*}$. We assume that Home's social planner seeks to maximize Home's social welfare. Let us denote by $L^{* *}$ the optimal allocation under Home's social planner. Given $\bar{Q}$, the first order condition of Home's welfare maximization is that the following equation holds at $L=L^{* *}$ :

$$
u^{\prime}\left(\frac{F(\bar{K}, L)}{n}\right)-\sigma D^{\prime}(F(\bar{K}, L)-\bar{Q})=\frac{1}{F_{L}(\bar{K}, L)}
$$

It is easy to show that $L^{* *}(\bar{Q})$ is an increasing function of $\bar{Q}$, and hence $Y^{* *}$ is increasing in $\bar{Q}$. We can prove the following Proposition:

Proposition 5: Assume Home is allowed to dump waste (without any cost) to Foreign, up to a limit $\bar{Q}>0$ where $\bar{Q}$ is smaller then the optimum output level of the closed economy, $Y^{*}$. Then in the control and command scenario where social welfare is maximized, an increase in $\bar{Q}$ will lead to

(i) an increase in output, $Y$, and

(ii) a fall in the quantity of domestic waste remaining,

(iii) an increase in Home's social welfare.

Example 1.6 (control and command scenario, foreign quota on dumping of trash) 
Let $Y=F(K, L)=K^{1 / 2} L^{1 / 2}, D(Z)=\frac{1}{2} Z^{2}$, where $Z \equiv \min \{Y-\bar{Q}, 0\}$, and $u^{\prime}(y)=$ $A-b y$. Let $\bar{K}=1$ for simplicity. Given $\bar{Q}$, the social planner chooses the employment level in manufacturing to maximize the social welfare,

$$
[\bar{L}-L]+n A\left[\frac{2 L^{1 / 2}}{n}\right]-\frac{n b}{2}\left[\frac{2 L^{1 / 2}}{n}\right]^{2}-\frac{\sigma}{2}\left[2 L^{1 / 2}-\bar{Q}\right]^{2}
$$

We obtain the first order condition, which may be re-arranged to yield

$$
(A+\sigma \bar{Q}) L^{-1 / 2}=\left(1+\frac{2 b}{n}+2 \sigma\right)
$$

This yields the optimal manufacturing output

$$
Y^{* *}=\frac{2 n(A+\sigma \bar{Q})}{(n+2 b+2 \sigma n)} .
$$

Thus, comparing $Y^{* *}$ with the socially optimal manufacturing output $Y^{*}$ in the closed economy case, we have

$$
Y^{* *}=Y^{*}+\frac{2 n \sigma \bar{Q}}{n+2 b+2 \sigma n}
$$

If $\bar{Q}$ is increased by 1 unit, the social planner will increase the manufacturing output by less than 1 unit.

The amount of trash remaining in the Home country is

$$
Y^{* *}-\bar{Q}=\frac{2 n A}{(n+2 b+2 \sigma n)}-\bar{Q}\left[1-\frac{2 n \sigma}{n+2 b+2 \sigma n}\right]>0
$$

and this amount falls as $\bar{Q}$ increases:

$$
\frac{d\left(Y^{* *}-\bar{Q}\right)}{d \bar{Q}}=-\frac{n+2 b}{n+2 b+2 \sigma n}<0
$$

For a numerical illustration, consider $n=10, \bar{L}=20, b=2, \sigma=2, A=5, \bar{Q}=1$. Then, using eq. (84), we obtain $Y^{* *}=2.6923$. That is, when the economy can $\operatorname{dump} \bar{Q}$ abroad, its optimal manufacturing output increases by about 40 per cent. Manufacturing employment is $L^{* *}=1.8121$. The amount trash that remains in Home is 1.6923 , so that the level of pollution in Home falls by 12 per cent. Social welfare is :

$$
(20-1.8121)+10\left(\frac{5 \times 2.6923}{10}\right)-10\left(\frac{2.6923}{10}\right)^{2}-(1.6923)^{2}=28.061
$$

which is 13 per cent greater than the corresponding welfare in a closed economy. 


\subsubsection{The equilibrium political economy allocation (with limited free dumping)}

Assume that group 3 is not organized: its members do not take collective action. Then, given that a positive fraction $1-\lambda_{0}$ of the population does not belong to any organized interest group, the political economy equilibrium in the presence of a free dumping quota $\bar{Q}$ is characterized by the following first order condition, which is an obvious generalization of eq. (74):

$$
\left[t-n \bar{\beta} D^{\prime}(\widehat{Y}(t)-\bar{Q})\right]+\frac{\left(1-\lambda_{0}\right)}{\left(\delta+\lambda_{0}\right)}\left\{\left(n \bar{\beta}_{M}-n \bar{\beta}\right) D^{\prime}(\widehat{Y}(t)-\bar{Q})-\left(\frac{F_{L L}}{F_{L}^{3}}\right) \widehat{Y}(t)\right\}=0
$$

Then, thanks to Assumption A2, we can deduce that the political economy equilibrium tax rate is below the Pigouvian one: $t<\sigma D^{\prime}(Z)$.

Example 1.7 (Political-economy equilibrium for an economy with limited free disposal of trash abroad) We retain the specifications of examples 1.5 and 1.6. Define $\phi \equiv\left(1-\lambda_{0}\right) /\left(\delta+\lambda_{0}\right), \sigma=n \bar{\beta}$ and $\sigma^{+}=n \bar{\beta}_{M}$, and $\varepsilon \equiv \sigma^{+}-\sigma>0$,

Solving eq. (88), we obtain the political economy equilibrium tax rate, $t$ :

$$
t=(\sigma-\phi(\varepsilon+0.5)) \widehat{Y}(t)-(\sigma-\phi \varepsilon) \bar{Q}
$$

We will look at different values of $\bar{Q}$ : high, medium, low. In all cases, we set $n=10, \bar{L}=$ 20, $A=5, b=1, \sigma=2, \varepsilon=0.5, \phi=0.5$ (as in example 1.5)

(i) High $\bar{Q}$ : Assume $\bar{Q}=1$. Then direct computation yields $t=3.0714$. The manufacturing output is 3.2143 and manufacturing employment is $L=2.5829$. The quantity of trash that remains in Home is $Z=Y-\bar{Q}=2.2143$. Social welfare is

$$
W=(20-2.5829)+5 \times 3.2143-10\left(\frac{3.2143}{10}\right)^{2}-(2.2143)^{2}=27.552
$$

Thus, given this particular set of parameter specifications, in the political-economy equilibrium while social welfare level is lower (as expected) than under the control and command scenario with foreign quota on free disposal of waste, it is higher than the welfare level under the command and control in a closed economy(which was 24.807), though the trash level 
at Home, $Z=2.2143$, is higher than under the command and control in a closed economy (which was 1.9231). Interestingly, there is more output but also more trash (compared to command and control outcome in a closed economy).

For comparison, consider somewhat lower values of $\bar{Q}$.

(ii) Medium $\bar{Q}$. Assume $\bar{Q}=0.5$. Then $t=3.3214, Y=2.7977, L=1.9568$, and the trash that remains in Home is $Z=2.2977$. Welfare is 25.970.

(iii) Low $\bar{Q}$. Assume $\bar{Q}=0.15$. Then $t=3.4964, Y=2.506, L=1.57, Z=2.356$, and welfare is 24.781 .

\subsubsection{The effect of an increase in the leakage factor}

Recall that for every dollar that lobby group sends to the government, the latter only receives a fraction $(1-\gamma)$, where $\gamma$ is the called the leakage factor. We expect that an increase in the leakage factor will make the lobby groups less effective.

Now an increase in $\gamma$ translates into a smaller $\phi$. So, let us modify example 1.7 (above) by replacing $\phi=0.5$ with $\phi=0.2$, while the low $\bar{Q}$ remains at 0.15 . Computing the new political economy equilibrium, we find that $t=3.6788, Y=2.202, L=1.2122, Z=1$. 2122 , and welfare is 25.102 , which is greater than 24.781 .

\subsection{Costly disposal of trash}

In fact, except for illicit activity, most trash export destinations demand the payment of disposal costs, substantial bribes, or reparations of some form. For now we ignore the form of disposal, but this is worldwide a highly charged issue.

Denote by $\mu$ the price of disposing of a unit of waste through export. Clearly the price of export must be cheaper than the forgone opportunity to simply reduce production of $Y$ or else firms could be paid more to simply not produce so much.

Since we observe that some trash remains in the country of origin, it must be the case that there are some reasons for the absence of a corner solution (whereby either all the trash would be exported, or all would stay in the country of origin). A plausible explanation is that the 
exportation of all the trash generated would require the use of real resources in the collecting and sorting of trash, as well as the packaging and transportation of trash to conform with the requirements of the destination countries. Such activities are likely to be be subject to increasing marginal costs. A simple way to model this increasing cost is to assume that the trash exporting country must use labor in these activities, which is subject to diminishing returns. We suppose that for $Q$ units of trash exported, the required amount of labor in the collecting and sorting activities is $\eta(Q)$, where $\eta(0)=0, \eta^{\prime}(Q)>0$ and $\eta^{\prime \prime}(Q)>0$. Let $L$ denote the amount of labor used in the production of the manufactured goods $Y$, and $\eta(Q)$ denote the amount of labor used in the trash collection and sorting activities. Then the remaining quantity of labor, $\bar{L}-L-\eta(Q)$, is used to produce the numeraire good.

We will look briefly at the planner's solution, and compare it with the outcome under the political economy equilibrium.

\subsubsection{The planner's solution}

Denote by $\mu$ the foreign charge per unit of trash exported. The social planner takes $\mu$ as given, and chooses $L$ and $Q$ to maximize social welfare

$$
W=[\bar{L}-L-\eta(Q)-\mu Q]+n u\left(\frac{F(\bar{K}, L)}{n}\right)-\sigma D(F(\bar{K}, L)-Q)
$$

For simplicity we assume that the solution is an interior one, i.e., $Q<F(\bar{K}, L)$. The first order conditions are

$$
\begin{gathered}
\frac{\partial W}{\partial Q}=-\mu-\eta^{\prime}(Q)+\sigma D^{\prime}(Z)=0 \text { where } Z=F(\bar{K}, L)-Q \\
\frac{\partial W}{\partial L}=-1+\left[u^{\prime}\left(\frac{F(\bar{K}, L)}{n}\right)-\sigma D^{\prime}(Z)\right] F_{L}=0
\end{gathered}
$$

Equation (93) is by now familiar. Equation (92) says that at the optimum, the marginal cost of exporting is equated to its marginal benefit (the reduction in pollution damages). Using equation (92), we can express $Q^{*}$ as a function of $L$ and $\mu$, i.e., $Q^{*}=Q^{*}(L, \mu)$. Then

substituting $Q^{*}(L, \mu)$ into eq. (93), we have a single equation to determine $L^{*}$. To illustrate 
the procedure, suppose for simplicity that $\eta(Q)=(\kappa / 2) Q^{2}$ and $D(Z)=(1 / 2) Z^{2}$. Then equation (92) becomes

$$
-\mu-\kappa Q+\sigma[F(\bar{K}, L)-Q]=0
$$

from which we obtain

$$
Q^{*}=\frac{\sigma F(\bar{K}, L)-\mu}{\kappa+\sigma}
$$

and thus eq. (93) becomes

$$
u^{\prime}\left(\frac{F(\bar{K}, L)}{n}\right)-\sigma\left[F(\bar{K}, L)-\frac{\sigma}{\sigma+\kappa} F(\bar{K}, L)+\frac{\mu}{\sigma+\kappa}\right]=\frac{1}{F_{L}}
$$

This equation yields $L^{*}$.

Example 1.8. Let $Y=F(K, L)=K^{1 / 2} L^{1 / 2}, \eta(Q)=(\kappa / 2) Q^{2}, D(Z)=\frac{1}{2} Z^{2}$, and $u^{\prime}(y)=A-b y$. Let $\bar{K}=1$ for simplicity. Assume $A>\sigma \mu /(\sigma+\kappa)$. Then

$$
\begin{gathered}
A-b\left(\frac{2 L^{1 / 2}}{n}\right)-\sigma\left(1-\frac{\sigma}{\sigma+\kappa}\right) 2 L^{1 / 2}-\frac{\sigma \mu}{\sigma+\kappa}=L^{1 / 2} \\
\left(A-\frac{\sigma \mu}{\sigma+\kappa}\right)=\left[1+\frac{2 b}{n}+2 \sigma\left(1-\frac{\sigma}{\sigma+\kappa}\right)\right] L^{1 / 2}
\end{gathered}
$$

Solving for $L^{1 / 2}$,

$$
L^{1 / 2}=\frac{n(A(\sigma+\kappa)-\sigma \mu)}{(\sigma+\kappa)(n+2 b)+2 n \kappa \sigma}
$$

The optimal output is

$$
Y^{o p t}=\frac{2 n(A(\sigma+\kappa)-\sigma \mu)}{(\sigma+\kappa)(n+2 b)+2 n \kappa \sigma}
$$

the optimal export of trash is

$$
Q^{o p t}=\frac{\sigma Y^{o p t}-\mu}{\kappa+\sigma}=\frac{1}{\kappa+\sigma}\left[\frac{2 \sigma n(A(\sigma+\kappa)-\sigma \mu)}{(\sigma+\kappa)(n+2 b)+2 n \kappa \sigma}-\mu\right]
$$

and the optimal quantity of trash that remains in the Home country is

$$
Z^{o p t}=\frac{\kappa}{\kappa+\sigma}\left(\frac{2 n(A(\sigma+\kappa)-\sigma \mu)}{(\sigma+\kappa)(n+2 b)+2 n \kappa \sigma}\right)+\frac{\mu}{\kappa+\sigma}
$$

Remark: It can be verified that the social optimum can be achieved by taxing manufacturing output at a rate $t$ that is equal to the marginal social cost of pollution, $\sigma D^{\prime}\left(Z^{o p t}\right)$, 
which will be refunded upon the trash being exported. That is, the manufacturing firms decide how much to produce and how much trash to be exported, taking as given the consumers price, $p_{c}$, the tax rate $t$ on manufacturing output, which is also the refund per unit of trash exported. Under the above assumptions, the profit of the representative firm is

$$
\pi=\left(p_{c}-t\right) F(\bar{K}, L)-L+(t-\mu) Q-\eta(Q)
$$

which the firm maximizes by choosing $L$ and $Q$.

Assuming an interior solution, we obtain the firm's first order condition with respect to $Q$

$$
(t-\mu)=\eta^{\prime}(Q)
$$

From which we deduce the trash export supply function

$$
\widehat{Q}(t)=Q(t-\mu)
$$

The firm's the first order condition with respect to $L$ is

$$
\left(p_{c}-t\right) F_{L}=1
$$

Using the consumer's equilibrium condition that $u^{\prime}(y)=p_{c}$ to substitute for $p_{c}$, we obtain

$$
u^{\prime}\left(\frac{(\bar{K}, L)}{n}\right)-t=\frac{1}{F_{L}}
$$

from which we obtain the output $\widehat{Y}(t)$. It follows that if the government set $t=t^{\text {opt }}=$ $\sigma D^{\prime}\left(Z^{o p t}\right)$, then the command and control social optimum can be achieved by a competitive market.

\subsubsection{The political economy equilibrium (the open economy case, with costly export of trash)}

In this subsection, we consider the political economy outcome in the open economy where the two organized pressure groups are group 1 and group 2. Group 3 is not organized and 
therefore does not make campaign contributions. As before, we assume that the government seeks to maximize the objective function $\widetilde{G}(t)$ defined by

$$
\widetilde{G}(t)=\left(\frac{\omega}{\rho}\right) J^{g r o s s}(t)+\sum_{h \in \Lambda} \psi_{h}(t) \equiv \delta J^{\text {gross }}+\sum_{h \in \Lambda} \psi_{h}(t)
$$

Because of the opportunity to export trash in order to get a tax refund, firms solve the profit maximization problem

$$
\max _{L, Q}\left\{p_{f}(t) F(\bar{K}, L)-w+(t-\mu) Q-\eta(Q)\right\} \equiv \pi(t)
$$

where $p_{f}(t)=p_{c}(t)-t$. Using the envelope theorem, we obtain

$$
\frac{d \pi}{d t}=\widehat{Q}+\left[\frac{d p_{f}}{d t}\right] \widehat{Y}, \text { where } \widehat{Y} \equiv F(\bar{K}, \widehat{L} .)
$$

While the government collects the tax $t \widehat{Y}$, it must pay a refund $t \widehat{Q}$ upon the exportation of trash. Therefore, the net tax revenue is $t[\widehat{Y}-\widehat{Q}]$, which is distributed as lump sums to all consumers: each consumer gets $(1 / n) t[\widehat{Y}-\widehat{Q}]$.

The gross welfare of the group of $m_{1}$ capital-owners is

$$
\begin{aligned}
J_{1}= & \pi\left(p_{c}(t)-t\right)+ \\
& +m_{1}\left[\bar{\ell}+S\left(p_{c}(t)\right)\right]+\frac{m_{1}}{n} t[\widehat{Y}-\widehat{Q}]-m_{1} \bar{\beta}_{C} D[\widehat{Y}-\widehat{Q}]
\end{aligned}
$$

The gross welfare levels of the two consumer groups are

$$
\begin{aligned}
& J_{2}=m_{2}[\bar{\ell}+S(p(t))]+\frac{m_{2}}{n} t[\widehat{Y}-\widehat{Q}]-m_{2} \bar{\beta}_{E} D[\widehat{Y}-\widehat{Q}] \\
& J_{3}=m_{3}[\bar{\ell}+S(p(t))]+\frac{m_{3}}{n} t[\widehat{Y}-\widehat{Q}]-m_{3} \bar{\beta}_{M} D[\widehat{Y}-\widehat{Q}]
\end{aligned}
$$

where, as before, we assume that $\bar{\beta}_{C} \leq \bar{\beta} \leq \bar{\beta}_{M} \leq \bar{\beta}_{E}$.

Note that

$$
\begin{aligned}
\frac{d J_{1}}{d t=} & {\left[\frac{d p^{c}}{d t}-1\right] \widehat{Y}+\widehat{Q}-m_{1} y^{D} \frac{d p^{c}}{d t}+} \\
& \frac{m_{1}}{n}\left[\widehat{Y}-\widehat{Q}+t\left(\frac{d \widehat{Y}}{d t}-\frac{d \widehat{Q}}{d t}\right)\right]-m_{1} \bar{\beta}_{C} D^{\prime}(Z)\left(\frac{d \widehat{Y}}{d t}-\frac{d \widehat{Q}}{d t}\right)
\end{aligned}
$$




$$
\begin{aligned}
\frac{d J_{2}}{d t}= & -m_{2} y^{D} \frac{d p^{c}}{d t}+ \\
& \frac{m_{2}}{n}\left[\widehat{Y}-\widehat{Q}+t\left(\frac{d \widehat{Y}}{d t}-\frac{d \widehat{Q}}{d t}\right)\right]-m_{2} \bar{\beta}_{E} D^{\prime}(Z)\left(\frac{d \widehat{Y}}{d t}-\frac{d \widehat{Q}}{d t}\right)
\end{aligned}
$$

and

$$
\begin{aligned}
\frac{d J_{3}}{d t}= & -m_{3} y^{D} \frac{d p^{c}}{d t}+ \\
& \frac{m_{3}}{n}\left[\widehat{Y}-\widehat{Q}+t\left(\frac{d \widehat{Y}}{d t}-\frac{d \widehat{Q}}{d t}\right)\right]-m_{3} \bar{\beta}_{M} D^{\prime}(Z)\left(\frac{d \widehat{Y}}{d t}-\frac{d \widehat{Q}}{d t}\right)
\end{aligned}
$$

The government's choice of $t$ must satisfy the following first order condition

$$
\left[t-n \bar{\beta} D^{\prime}(\widehat{Y}(t)-\widehat{Q}(t))\right]+\frac{1-\lambda_{0}}{\delta+\lambda_{0}}\left\{\left(n \bar{\beta}_{M}-n \bar{\beta}\right) D^{\prime}(\widehat{Y}(t)-\widehat{Q}(t))-\left(\frac{F_{L L}}{F_{L}^{3}}\right) \widehat{Y}(t)\right\}=0
$$

where $\lambda_{0} \equiv\left(m_{1}+m_{2}\right) / n$ is the fraction of the population that belongs to an organized group.

Thus we can state:

Proposition 6: Assume that the government chooses the tax $t$ on manufacturing output (which is refunded to trash exporters) in order to maximize its objective function (108) which is a weighted sum of net social welfare and receipts of campaign contribution. If group 3 is unorganized, then the politically chosen tax $t$ is below the Pigouvian level.

We conclude that the opportunity to export waste in unlimited quantities, but at a price, is not the environmentalists' panacea and does not eliminate political social tension and suboptimal results.

\section{Concluding remarks}

In this model, with or without trade in externality, the optimal planning solution will never be achieved by politics if the industry lobby has any influence at all, as long as the enviromental lobby cannot mobilize all the consumers. The possibility of tradeable trash will reduce social tension if the environmentalists care only about pollution in their home country. Domestic 
firms will always favor a policy of trash exports over output reduction to achieve the social goal of reduced waste.

A more burning gap in the story is ignoring the consequence abroad of tradeable trash. There will be an imported negative externality and so a political social debate abroad. Also, there may be terms of trade effects or, as seems the case with trash, a bias in import eagerness toward poorer countries that either need the money or have no environmental influence in government decisions.

\section{References}

[1] Bags, J., 2009. International trade in hazardous waste. Rev. Internat. Econ. 17(1), 1-16.

[2] Baldwin, R. E., Magee, C. S., 1998. Is trade policy for sale? Congressional voting on recent trade bills. NBER Working Paper No. 6376. Cambridge MA.

[3] Bernheim, B. D., Whinston, M. D., 1986. Menu auctions, resource allocation, and economic influence. Q. J. Econ. 101, 1-31.

[4] Bommer, R., Schulze, G. G., 1999. Environmental improvement with trade liberalization. Eur. J. Polit. Econ. 15(4), 639-661.

[5] Cassing, J. H., Hillman, A.L., 1986. Shifting comparative advantage and senescent industry collapse. Am. Econ. Re. 78. 516-523.

[6] Cassing, J. H., Kuhn, T., 2003a. The political economy of strategic environmental policy when waste products are tradeable. In: Singer, H, Hatti, N., R. Tandon, R. (Eds.), Trade and Environment: Recent Controversies. New World Order Series. BR Publishing Corporation, Delhi, pp. 101-118.

[7] Cassing, J. H., Kuhn, T., 2003b. Trade and the environment. Jährbuch für Regionalwissenschaft (Annals of Regional Science), pp. 23-38. 
[8] Cassing, J. H., Kuhn, T., 2003c. Trade in trash: optimal environmental policy in the presence of international trade in waste. Rev. Internat. Econ. 11(3), 496-511.

[9] Copeland, B. R., Taylor, M. S., 2004. Trade, growth, and the environment. J. Econ. Lit. 42, 7-71.

[10] Ethier, W. J., Hillman, A. L., 2019. The politics of international trade policy. In: Congleton, R. D., Grofman, B.N., Voigt, S. (Eds.), volume 2, chapter 12. Oxford Handbook of Public Choice. Oxford University Press, Oxford, UK, pp. 653-683.

[11] Feenstra, R. C., 2016. Advanced International Trade. Princeton University Press, Princeton NJ.

[12] Fredriksson, P. G., 1999. The political economy of trade liberalization and environmental policy. Southern Econ. J. 513-525.

[13] Gawanda, K., Bandyopadhay, U., 2000. Is protection for sale? Evidence on the Grossman-Helpman theory of endogenous protection. Rev. Econ. Stat. 82(1), 139-152.

[14] Goldberg, P. K., Maggi, G., 1999. Protection for sale: An empirical investigation. Am. Econ. Rev. 89 (5), 1135-1155.

[15] Grafton, Q., Kompas, T., Long, N. V., 2017. A brave new world? Kantian-Nashian interaction and the dynamics of global climate change mitigation. Eur. Econ. Rev. 99(C), 31-42.

[16] Grossman, G. M., Helpman, E., 1994. Protection for Sale. Am. Econ. Rev. 80(4), 833850.

[17] Hillman, A. L., 1982. Declining industries and political support protectionist motives. Am. Econ. Rev. 72, 1180-1187. 
[18] Hillman, A. L. (2019). Public Finance and Public Policy: A Political Economy Perspective on the Responsibilities and Limitations of Governments. (Third Edition.) Cambridge University Press, Cambridge, UK.

[19] Hillman, A. L., Ursprung, H. W. 1992. The influence of environmental concerns on the political determination of international trade policy. In: Anderson, K., Blackhurst, R. (Eds.), The Greening of World Trade Issues. University of Michigan Press, Ann Arbor MI, pp. 195-220.

[20] Hillman, A. L., Ursprung, H. W. 1994. Greens, supergreens, and international trade policy: environmental concerns and protectionism. In: Carraro, C. (Ed.), Trade, Innovation, Environment. Springer, Heidelberg, pp. 75-108.

[21] Long, N. V., 2020. Warm glow and the transmission of pro-socialness across generations. J. Public Econ. Theor. 22(2). 371-387.

[22] Long, N. V., Vousden, N., 1991. Protectionist responses and declining industries. J. Internat. Econ. 30, 87-104.

[23] Mitra, D., 1999. Endogenous lobby formation and endogenous protection: a long-run model of trade policy determination. Am. Econ. Rev. 89(5), 1116-1134.

[24] Rauscher, M., 2001. International trade and hazardous waste. Thünen-Series of Applied Economic Theory,Working Paper No. 19. Universität Rostock, Institut für Volkswirtschaftslehre, Rostock.

[25] Rauscher, M., 2015. International trade, foreign investment, and the environment. In: Mähler K. G. , Vincent,J. R. (Eds.), Handbook of Environmental Economics, Volume 3, Chapter 17, Elsevier, North Holland, pp. 1403-1456.

[26] Schleich, J., 1999. Environmental quality with endogenous domestic and trade policies. Eur. J. Polit. Econ. 15(1), 53-71. 
[27] Schogen, J. F., Crocker, T., 1991. Cooperative and non-cooperative protection against transferable and filterable externalities. Environ. Res. Econ. 1(2). 195-214.

[28] Siebert, H., Eichberger, J., Gronych, R., Pethig, R., 1980. Trade and Environment: A Theoretical Enquiry. Volume 6 of Studies in Environmental Science. North Holland, Amsterdam,

[29] The Economist (1992). Let them eat pollution. 8 February, 1992. page 66.

\section{Appendix}

\section{Proof of Proposition 4}

When the government chooses $t$ to maximizes it objective function (65), the following first order condition is obtained:

$$
\begin{array}{ll} 
& (1+\delta)\left[\widehat{Y}\left(\frac{d p^{c}}{d t}-1\right)-m_{1} y^{D} \frac{d p^{c}}{d t}+\frac{m_{1}}{n}\left(\widehat{Y}+t \frac{d \widehat{Y}}{d t}\right)-m_{1} \bar{\beta}_{C} D^{\prime}(\widehat{Y}) \frac{d \widehat{Y}}{d t}\right] \\
& +(1+\delta)\left[-m_{2} y^{D} \frac{d p^{c}}{d t}+\frac{m_{2}}{n}\left(\widehat{Y}+t \frac{d \widehat{Y}}{d t}\right)-m_{2} \bar{\beta}_{E} D^{\prime}(\widehat{Y}) \frac{d \widehat{Y}}{d t}\right] \\
& +\delta\left[-m_{3} y^{D} \frac{d p^{c}}{d t}+\frac{m_{3}}{n}\left(\widehat{Y}+t \frac{d \widehat{Y}}{d t}\right)-m_{3} \bar{\beta}_{M} D^{\prime}(\widehat{Y}) \frac{d \widehat{Y}}{d t}\right] \\
= & 0
\end{array}
$$

The above equation can be re-written as follows

$$
\begin{aligned}
& \delta\left[\frac{d J}{d t}\right]+\left[-m_{2} y^{D} \frac{d p^{c}}{d t}+\frac{m_{2}}{n}\left(\widehat{Y}+t \frac{d \widehat{Y}}{d t}\right)-m_{2} \bar{\beta}_{E} D^{\prime}(\widehat{Y}) \frac{d \widehat{Y}}{d t}\right]+ \\
& {\left[\widehat{Y}\left(\frac{d p^{c}}{d t}-1\right)-m_{1} y^{D} \frac{d p^{c}}{d t}+\frac{m_{1}}{n}\left(\widehat{Y}+t \frac{d \widehat{Y}}{d t}\right)-m_{1} \bar{\beta}_{C} D^{\prime}(\widehat{Y}) \frac{d \widehat{Y}}{d t}\right]=0}
\end{aligned}
$$

Using $y^{D}=\widehat{Y} / n$, the above equation becomes

$$
\begin{aligned}
& \delta\left[\widehat{Y}\left(\frac{d p^{c}}{d t}-1\right)-n y^{D} \frac{d p^{c}}{d t}+\left(\widehat{Y}+t \frac{d \widehat{Y}}{d t}\right)-n \bar{\beta} D^{\prime}(\widehat{Y}) \frac{d \widehat{Y}}{d t}\right]+ \\
& {\left[\widehat{Y}\left(\frac{d p^{c}}{d t}-1\right)-\frac{\left(m_{1}+m_{2}\right) \widehat{Y}}{n} \frac{d p^{c}}{d t}+\frac{\left(m_{1}+m_{2}\right)}{n}\left(\widehat{Y}+t \frac{d \widehat{Y}}{d t}\right)-\sum_{i=1}^{m_{1}+m_{2}} \beta_{i} D^{\prime}(\widehat{Y}) \frac{d \widehat{Y}}{d t}\right] } \\
= & 0
\end{aligned}
$$


This equation reduces to

$$
\begin{aligned}
0= & \delta\left[t-n \bar{\beta} D^{\prime}(\widehat{Y})\right] \frac{d \widehat{Y}}{d t}+\left(\frac{m_{3}}{n}\right) \widehat{Y}\left(\frac{d p^{c}}{d t}-1\right) \\
& +\left[\frac{\left(m_{1}+m_{2}\right)}{n} t-D^{\prime}(\widehat{Y})\left(m_{1} \bar{\beta}_{C}+m_{2} \bar{\beta}_{E}\right)\right] \frac{d \widehat{Y}}{d t}
\end{aligned}
$$

Using equation (40) we can replace $\left(\frac{d p^{c}}{d t}-1\right)$ with $\left(-\frac{F_{L L}}{\left(F_{L}\right)^{3}}\right) \frac{d \widehat{Y}(t)}{d t}$ to obtain

$$
\begin{aligned}
0= & \delta\left[t-n \bar{\beta} D^{\prime}(\widehat{Y})\right] \frac{d \widehat{Y}}{d t}+\left(\frac{m_{3}}{n}\right) \widehat{Y}\left(-\frac{F_{L L}}{\left(F_{L}\right)^{3}}\right) \frac{d \widehat{Y}(t)}{d t} \\
& +\left[\frac{\left(m_{1}+m_{2}\right)}{n} t-D^{\prime}(\widehat{Y})\left(m_{1} \bar{\beta}_{C}+m_{2} \bar{\beta}_{E}\right)\right] \frac{d \widehat{Y}}{d t}
\end{aligned}
$$

Now, recall that by definition,

$$
n \bar{\beta}=m_{1} \bar{\beta}_{C}+m_{2} \bar{\beta}_{E}+m_{3} \bar{\beta}_{M}
$$

Therefore

$$
\begin{aligned}
m_{1} \bar{\beta}_{C}+m_{2} \bar{\beta}_{E} & =n \bar{\beta}-m_{3} \bar{\beta}_{M}=\left(\frac{m_{1}+m_{2}+m_{3}}{n}\right) n \bar{\beta}-m_{3} \bar{\beta}_{M} \\
& =\left(\frac{m_{1}+m_{2}}{n}\right) n \bar{\beta}-\frac{m_{3}}{\beta}\left(n \bar{\beta}_{M}-n \bar{\beta}\right)
\end{aligned}
$$

Then, letting $\lambda_{0}=\left(m_{1}+m_{2}\right) / n$, the first order equation (A.5) becomes

$$
\begin{aligned}
0= & \left(\delta+\lambda_{0}\right)\left[t-n \bar{\beta} D^{\prime}(\widehat{Y})\right] \frac{d \widehat{Y}}{d t} \\
& +\left(1-\lambda_{0}\right)\left\{\widehat{Y}\left(-\frac{F_{L L}}{\left(F_{L}\right)^{3}}\right)+\left(n \bar{\beta}_{M}-n \bar{\beta}\right) E^{\prime}(\widehat{Y})\right\} \frac{d \widehat{Y}}{d t}
\end{aligned}
$$

Since $\frac{d \widehat{Y}}{d t}<0$, the FOC reduces to

$$
\left[t-n \bar{\beta} D^{\prime}(\widehat{Y}(t))\right]+\frac{1-\lambda_{0}}{\delta+\lambda_{0}}\left\{\left(n \bar{\beta}_{M}-n \bar{\beta}\right) D^{\prime}(\widehat{Y}(t))-\left(\frac{F_{L L}}{F_{L}^{3}}\right) \widehat{Y}(t)\right\}=0
$$

Since the term inside the curly brackets $\{\ldots\}$ is positive, it follows that $t<n \bar{\beta} D^{\prime}(\widehat{Y}(t))$ 